
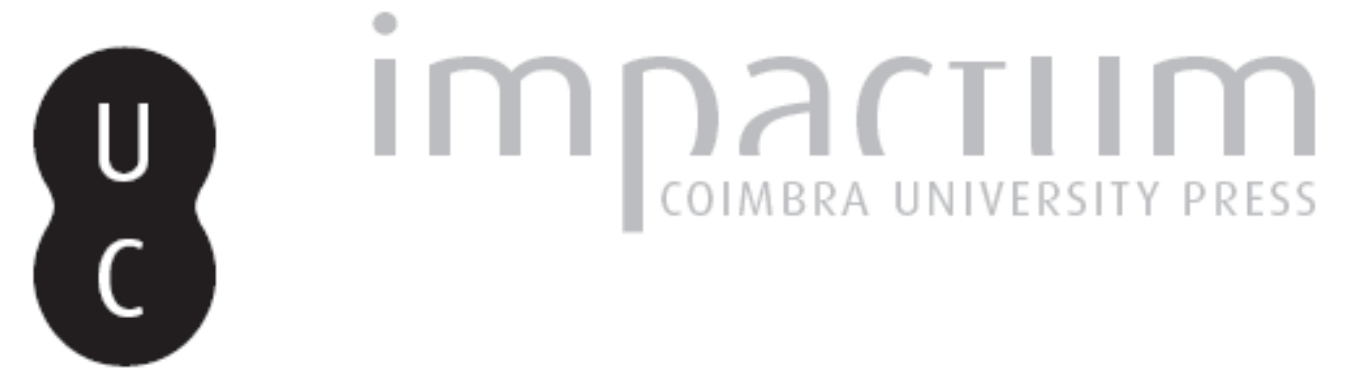

A Igreja de Nossa Senhora do Loreto: contributos para a sua história

Autor(es): $\quad$ Alberto, Edite Martins

Publicado por: Imprensa da Universidade de Coimbra

URL persistente:

URI:http://hdl.handle.net/10316.2/45635

DOI:

DOI:https://doi.org/10.14195/0870-8584_13_2

Accessed : $\quad$ 26-Apr-2023 08:33:54

A navegação consulta e descarregamento dos títulos inseridos nas Bibliotecas Digitais UC Digitalis, UC Pombalina e UC Impactum, pressupõem a aceitação plena e sem reservas dos Termos e Condições de Uso destas Bibliotecas Digitais, disponíveis em https://digitalis.uc.pt/pt-pt/termos.

Conforme exposto nos referidos Termos e Condições de Uso, o descarregamento de títulos de acesso restrito requer uma licença válida de autorização devendo o utilizador aceder ao(s) documento(s) a partir de um endereço de IP da instituição detentora da supramencionada licença.

Ao utilizador é apenas permitido o descarregamento para uso pessoal, pelo que o emprego do(s) título(s) descarregado(s) para outro fim, designadamente comercial, carece de autorização do respetivo autor ou editor da obra.

Na medida em que todas as obras da UC Digitalis se encontram protegidas pelo Código do Direito de Autor e Direitos Conexos e demais legislação aplicável, toda a cópia, parcial ou total, deste documento, nos casos em que é legalmente admitida, deverá conter ou fazer-se acompanhar por este aviso. 


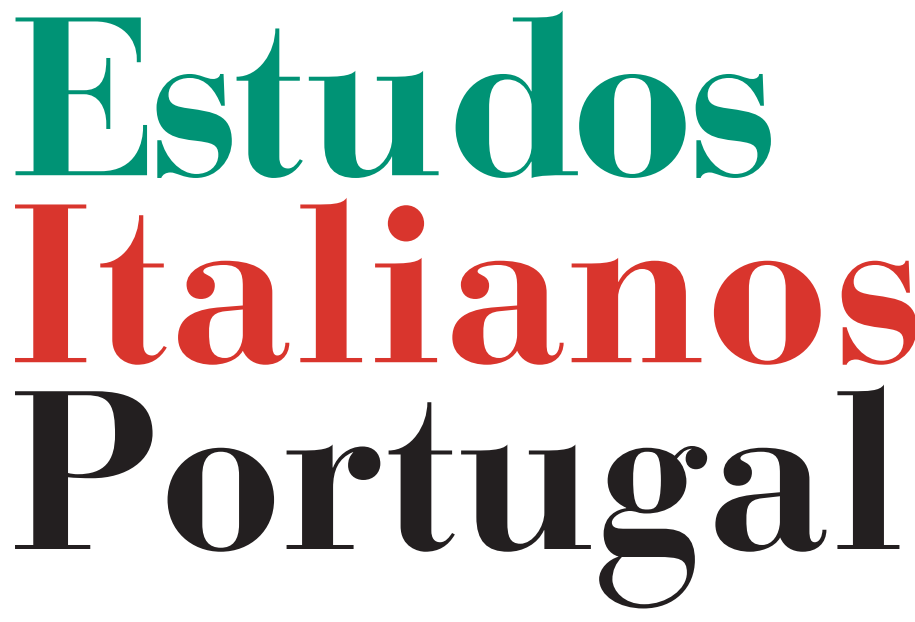

Instituto

Italiano

de Cultura

de Lisboa

Nova Série

$\mathrm{N}^{\mathbf{0}} 13$

2018 


\section{A IGREJA DE NOSSA SENHORA DO LORETO \\ DE LISBOA: CONTRIBUTOS \\ PARA A SUA HISTÓRIA}

Edite Martins Alberto *

Antes que fosse Lisboa Nem houvesse aqui cidade

Iam todos à Trindade

Com três cães e uma furoa

Caçar à sua vontade ${ }^{1}$.

Neste exCerto do Auto da Nau de Amores de Gil Vicente, apresentado pela primeira vez em 1527 nas festividades decorrentes da chegada a Lisboa da rainha D. Catarina de Áustria, o autor refere-se à parte ocidental fronteira à cidade como um lugar pouco habitado, propício à caça. Esta zona periférica, caracterizada pelos seus olivais e arvoredo variado, vinha-se estruturando em consequência da edificação das casas religiosas da Ordem da São Francisco e da Ordem da Santíssima Trindade, que pouco anos após a sua fundação e aprovação papal, se fixam em Lisboa ${ }^{2}$.

A Ordem dos Frades Menores, fundada por São Francisco de Assis, aprovada em 1209 pelo papa Inocêncio III, não tardou a espalhar-se pela Europa. Em Portugal, os primeiros conventos, na altura simples ermitérios, surgem em Alenquer, Guimarães, Coimbra e Lisboa durante o ano de 1217.

* Edite Martins Alberto é doutorada em História Moderna (ICS, Universidade do Minho), mestre em História dos Descobrimentos e da Expansão Portuguesa (FCSH NOVA) e investigadora integrada do CHAM-Centro de Humanidades da FCSH NOVA. editealberto@gmail.com

${ }^{1}$ Gil Vicente, Nau de Amores, J. V. Barreto Feio e J. C. Monteiro, Obras de Gil Vicente, Hamburgo, Officina Typographica de Langhoff, 1834, vol. 2, p. 307.

${ }^{2}$ Este artigo decorre da investigação efectuada no âmbito das actividades comemorativas dos 500 anos da existência do Bairro Alto. Sobre o assunto ver Hélder Carita (coord.), Bairro Alto. Mutaçôes e Convivências Pacíficas, Lisboa, Câmara Municipal de Lisboa, 2012. 
O convento de Lisboa foi edificado na colina denominada por Monte Fragoso, no local onde D. Afonso Henriques mandara edificar um oratório a Nossa Senhora dos Mártire ${ }^{3}$. Posteriormente ampliado e enriquecido, ficaria conhecido como Convento de São Francisco da Cidade

A Ordem da Santíssima Trindade e Redenção dos Cativos fora fundada em França, em 1198, por São João da Mata e São Félix de Valois, com o objectivo de prestar assistência e resgatar os cristãos cativos em terras muçulmanas. Em 1207 alguns frades trinitários passam por Lisboa a caminho da Terra Santa. Os danos sofridos na sua embarcação obrigaos a ficar algum tempo, durante o qual são recebidos por D. Sancho I, na altura com a corte em Santarém. O rei, ciente da importância que teria para o reino a presença dos frades, convida-os a fundar um convento em Santarém, disponibilizando para a sua instalação a ermida de Nossa Senhora da Abóbada, a pouca distância do palácio real ${ }^{4}$.

Poucos anos depois, em 1218, seria fundado um convento em Lisboa que se tornaria na casa principal da Ordem Trinitária em Portugal. Por intercessão do bispo de Lisboa, D. Sueiro Viegas, junto do rei D. Afonso II, e em consequência da conquista de Alcácer do Sal, na qual os frades trinitários tiveram importância fundamental, é-lhes concedida a ermida de Santa Catarina, então extramuros da cidade de Lisboa, para se fixarem ${ }^{5}$. Durante 71 anos serviu esta ermida de base

${ }^{3}$ Luiz Gonzaga Pereira, Monumentos Sacros em 1833, Lisboa, Oficinas Gráficas da Biblioteca Nacional, 1927, pp. 141-144; Manuel Ferreira da Silva, "S. Francisco da Cidade" Francisco Santana e Eduardo Sucena (dir.), Dicionário da História de Lisboa, Lisboa, 1994, pp. 798-800. Os edifícios do antigo convento de São Francisco albergam actualmente a Faculdade de Belas Artes da Universidade de Lisboa, a Academia de Belas Artes e o Museu de Arte Contemporânea.

${ }^{4}$ Sobre a história da Ordem da Santíssima Trindade em Portugal ver Edite Martins Alberto, Um negócio piedoso: o resgate de cativos em Portugal na época moderna, Tese de Doutoramento, Braga, Universidade do Minho, 2011.

${ }^{5}$ Frei Jerónimo de S. José, Historia da esclarecidade Ordem da SS. Trindade, Redempção de Cativos, da provincia de Portugal, Lisboa, Officina de Simão Thaddeo Ferreira, 1789, vol, I, p. 172. 
na organização dos resgates de cativos a sul do Tejo. Salientamos que numa altura de plena guerra de reconquista cristã do território peninsular, a presença destes frades dedicados ao resgate dos cristãos era de extrema importância. O aprisionamento de indivíduos ocorria de ambos os lados beligerantes - cristão e muçulmano - como consequência inerente ao conflito armado.

A ermida de Santa Catarina, com albergaria para leprosos, da época de D. Afonso II, foi integrada nas propriedades dos frades trinitários que vieram a construir um convento próprio com donativos da rainha Santa Isabel. As suas propriedades foram sendo alargadas com doaçōes régias e de particulares que instituíam capelas no convento trinitário ou o escolhiam para panteão da família. Em 1370, com a construção da nova cintura de muralhas pelo rei D. Fernando, o Convento da Trindade passa a situar-se no interior da cidade, bem junto à linha defensiva oriental de Lisboa. Tão perto que foi fundamental a acção dos religiosos aquando do cerco de João de Castela, em 1384, após a subida ao trono do Mestre de Avis, D. João I ${ }^{6}$.

No início do século XV o Convento da Trindade viu alargados os seus territórios com a doação testamentária de Constança Esteves, pela qual a Ordem ficava a usufruir de uma herdade com olival e campo agrícola, chamada do Olival ou da Oliveira, que ia até ao Postigo de São Roque. Este acesso da muralha devia o seu nome ao campo de São Roque, também pertença dos trinitários, posteriormente aforado aos padres jesuítas para fundação do seu convento ${ }^{7}$.

A instalação das casas conventuais das ordens religiosas nas encostas da colina fronteira à alcáçova, às quais se junta, em 1398, o convento dedicado a Santa Maria do Carmo da Ordem dos Carmelitas, fundado por D. Nuno Álvares Pereira,

\footnotetext{
${ }^{6}$ Fr. José de S. Jerónimo, cit., p. 179.

${ }^{7}$ Fr. José de S. Jerónimo, cit., p. 179.
} 


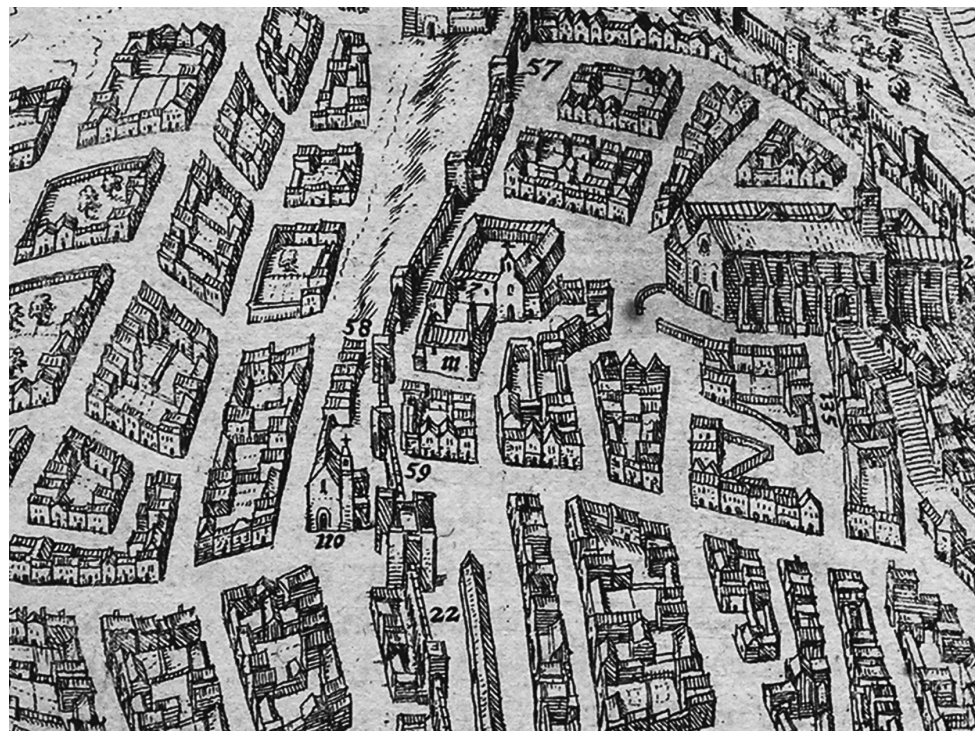

Fig. 1 Igreja de Nossa Senhora do Loreto, Convento da Santíssima Trindade e Convento do Carmo (George Braunio, Civitas Orbis Terrarum - Lisboa (pormenor), 1598, vol. V).

atraiu novos moradores e organizou o tecido urbano ${ }^{8}$. Este núcleo citadino, em formação, foi incluído no interior do perímetro da cerca fernandina, construída entre 1373 e 1375. A muralha vai alargar o limite da cidade, passando estas casas religiosas a integrarem o espaço interior da cidade. Durante o século XV, a numerosa população que se fixou na capital, consequência das actividades marítimas, instalou-se em grande parte na freguesia dos Mártires, sobretudo no exterior da muralha fernandina, formando sucessivos arrabaldes. A maior parte dos novos moradores dedicavam-se a actividades ligadas à vida fluvial e portuária. A esta circunstância juntaram-se os moradores que, em sequência, dos efeitos das sucessivas epidemias se deslocavam para fora da cidade, procurando melhores ares.

${ }^{8}$ Luiz Gonzaga Pereira, cit., pp. 81-84. 
Abertura de caminhos que articulavam a cidade com os novos arrabaldes, nomeadamente através das Portas de Santa Catarina e dos postigos de São Roque e do Duque, foi fundamental para o desenvolvimento das zonas exteriores à muralha. A memória das Portas de Santa Catarina está ainda hoje expressa no largo do Chiado através do modo como os dois edifícios (Igreja de Nossa Senhora do Loreto e a Igreja de Nossa Senhora da Encarnação) se encontram implantados. Do mesmo modo as ruas do Alecrim e da Misericórdia são herdeiras e sucedâneas dos caminhos exteriores à muralha medieval. A Calçada do Combro revela sobrevivência do antigo caminho rural para o termo da cidade?

A 16 de Dezembro de 1500, o rei D. Manuel ordena o derrube de todos os olivais que ficassem dentro das muralhas, independentemente a quem pertencessem, a fim de promover o aforamento por loteamentos, na tentativa de atenuar os efeitos do crescimento demográfico que se fazia sentir em Lisboa ${ }^{10}$. "O Bairro Alto não é porém, como se tem pensado, a primeira experiência urbanística em termos da cidade moderna. Dentro das muralhas, logo após as primeiras determinações régias de D. Manuel, nasce a Vila Nova do Olival onde, embora em menor escala, se encontram os princípios ditados pelo Rei. Das cercas dos frades Trinos e do Carmo, vai nascer a partir de 1502 um pequeno bairro, na altura chamado Vila Nova do Olival ou da Oliveira, cuja imagem revela afinidade, tanto a nível urbanístico como arquitectónico, com o Bairro Alto" ${ }^{11}$. Esta experiência constituiu o mo-

${ }^{9}$ A praça Luís de Camôes é relativamente recente, urbanizada no século XIX após a destruição de velhos edifícios, nomeadamente os palácios dos condes de Pontével e do marquês de Marialva, e dos casebres do Loreto.

${ }^{10}$ Arquivo Nacional Torre do Tombo (ANTT), Livro $1^{\circ}$ da Estremadura, fls. 160160v., Alvará real porque he determinado que todollos olivaes de muro a dentro se cortem. Este alvará encontra-se transcrito por Hélder Carita, Lisboa Manuelina e a Formação de Modelos Urbanisticos da Época Moderna (1495-1521), Lisboa, Livros Horizonte, 1999 , p. 215.

${ }^{11}$ Hélder Carita, cit., p. 18. 
delo para futuras urbanizações, na medida em que assentava no processo moderno de loteamento e na regulamentação e normalização de aspectos construtivos referentes à própria composição de volumes arquitectónicos ${ }^{12}$. "O alinhamento contínuo das fachadas dos edifícios, a largura das ruas, a recorrência quase sistemática a alvenaria de tijolo e pedra, as janelas de sacada de pedra de dois palmos constituem-se como pressupostos urbano-arquitectónicos ditados pelo Rei e que encontraremos, pouco tempo depois, sistematizados em maior escala, primeira na Vila Nova de Andrade e posteriormente no Bairro Alto de São Roque"13.

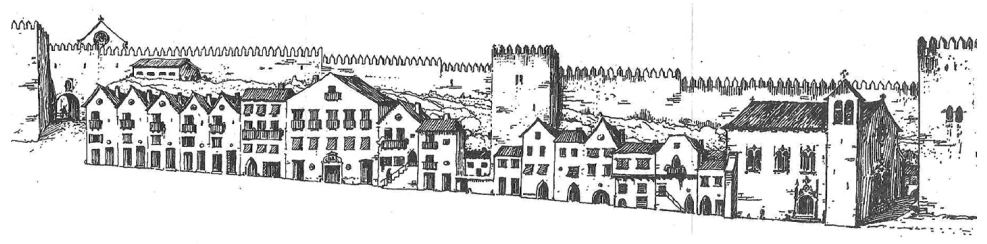

Fig. 2 Igreja de Nossa Senhora do Loreto na rua Larga de São Roque (hoje rua da Misericórdia) extramuros da cidade - século XVI (Gustavo Matos Sequeira, O Carmo e a Trindade. Lisboa, Câmara Municipal de Lisboa, 1939, vol. I, pp. 288-289, desenho de Alberto Sousa).

No ano de 1553, como anteriormente referido, os Jesuítas instalam-se em São Roque. Chegados a Portugal em 1540, fruto das conversações estabelecidas entre D. João III e Diogo de Gouveia, director do colégio de Santa Bárbara de Paris, os religiosos instalaram-se primeiro no convento de Santo Antão. Mais tarde, em 1553, estabelecem na zona ocidental da cidade a sua Casa Professa, na ermida de São Roque doada por D. João III à Companhia. Este pequeno santuário, que se erguia fora da muralha fernandina, perto das Portas de Santa Catarina e perto da Torre de Álvaro

${ }^{12}$ Maria Calado e Vítor Matias Ferreira, Lisboa freguesia da Encarnação (Bairro Alto), Lisboa, Contexto Editora, 1992. p. 29.

${ }^{13}$ Hélder Carita, cit., p. 18. 
Pais, fora construído no reinado de D. Manuel para nele se venerarem as relíquias de São Roque, enviadas de Veneza, como santo protector contra a peste. D. João III cede-o aos religiosos jesuítas na condição de conservarem sempre na igreja o título e invocação do santo. A cerimónia religiosa oficializando a doação ocorreu no dia 1 de Outubro de 1553 com a presença do monarca, do príncipe $\mathrm{D}$. João, do infante D. Luís, do arcebispo de Lisboa D. Fernando de Vasconcelos, da corte e da população atraída pela solenidade ${ }^{14}$. A cerimónia foi aberta pelo padre Francisco de Borja que então se achava em Lisboa e que fez a pregação evocativa do momento. Desde esse dia começaram os religiosos a habitar junto da ermida, em duas casas térreas, com alfaias religiosas emprestadas pelo colégio de Santo Antão. No entanto, desde cedo se começou a sentir a necessidade de ampliar as pequenas dimensões do local onde estavam os religiosos. Situação que D. João III chamou a si, tomando à sua conta o traçado da nova casa e da igreja. Para tal o monarca contribuiu com a sua fazenda tal como os principais senhores nobres da cidade de Lisboa ${ }^{15}$. "Junto da habitação estendeu-se logo do princípio e murou-se uma espaçosa cerca no terreno que para os padres comprara D. João III, e amenizou-se com fresca horta e pomar de boa fruta, de modo que fosse de utilidade e recreação para os moradores da casa" ${ }^{16}$.

Em Janeiro de 1555 escrevia o padre Gonçalo da Silveira, primeiro superior da comunidade e Igreja de São Roque, ao padre Inácio de Loiola: "o sítio em que habitamos é muito acomodado e sadio. Antes de nos transferirmos para cá, era deserto; cobriam-no hortas, olivais e esterquilínios: ago-

${ }^{14}$ Francisco Rodrigues, História da Companhia de Jesus na Assistência de Portugal, Porto, Apostolado da Imprensa, 1931, vol. I, pp. 623-625.

${ }^{15}$ Sobre a importância dos Jesuítas junto da corte ver João Francisco Marques, "Os Jesuítas, confessores da corte portuguesa na época barroca (1550-1700)”, Revista da Faculdade de Letras, Porto, 1995, pp. 231-270.

${ }^{16}$ Francisco Rodrigues, cit., p. 627. 
ra construem-se muitas casas; os olivais transformam-se em povoado; corre-se finalmente ao odor da suavidade. Bendito seja Deus" ${ }^{\prime \prime}$.

A 27 de Junho de 1555 dá-se o lançamento da primeira pedra da nova igreja. A antiga ermida que, de oriente a poente, tinha a extensão de cerca de dezassete metros, passou a constituir o corpo do novo templo. Na torre avistada de toda a Lisboa, foi colocado um relógio de grande dimensão que regulava com os sinais das horas e dos quartos a boa ordem da igreja e da casa, e servia também para grande parte da cidade $^{18}$. A nova igreja abre ao culto em 1573, mantendo-se as obras pelo século XVII. A casa professa principiou com cinco padres e, a partir de 1590 , seu número oscilou entre vinte e trinta. $\mathrm{O}$ cronista da ordem, Baltasar Teles salienta a caridade com que seus padres tratavam os empestados nas epidemias que ocorreram na cidade nos anos de 1569, 1579 e $1598^{19}$. "Nesta nova cidade, edificada de novo, no bairro alto, cheios de gente nobre e fidalgos ilustres; os valados toscos se trocaram em formosas ruas; o campo se fez cidade, o monte se converteu em corte e o sítio deserto se viu mudado em copiosa povoação, de sorte, que representa hoje aquele bairro huma bastante cidade... ${ }^{20}$.

No Livro do lançamento e serviço que a cidade de Lixboa fez a el rei nosso senhor o ano de 1565, onde se registam as parcelas pagas por cada morador de acordo com o Regimento do lançamento, a fim de refazer um total de 100 mil cruzados para ajuda na fazenda real, surge o registo dos contribuintes

${ }^{17}$ Francisco Rodrigues, cit. p. 633.

${ }^{18}$ Francisco Rodrigues, cit. p. 628.

${ }^{19}$ Nuno da Silva Gonçalves, "Baltasar Teles, Cronista da Companhia de Jesus", Quando os frades faziam História de Marcos de Lisboa a Simão de Vasconcellos, dir. José Adriano de Freitas Carvalho, Porto, Centro Universitário de História da Espiritualidade, 2001, p. 99.

${ }_{20}$ Baltasar Teles, Chronica da Companhia de Jesu na provincia de Portugal [...], Lisboa, Paulo Craesbeeck, 1645-1647, vol. 2, p. 101. 
por cada rua da cidade ${ }^{21}$. Apesar de excluindo os privilegiados, este livro constitui uma fonte fundamental para a caracterização social do Bairro Alto. Com base na freguesia do Loreto que neste livro abrange ruas como as de São Roque, dos Calafates, Direita do Loreto, da Atalaia, Rosa das Partilhas, dos Fiéis de Deus, entre outras, registamos mais de 500 referências a ofícios ${ }^{22}$. As profissões relacionadas com o mar e com a construção civil são as que mais se destacam. Encontramse cerca de oitenta ofícios relacionados com as actividades marítimas como pilotos, mestres, contramestres, barqueiros, marinheiros, pescadores, calafates, e mais de centena e meia de ofícios inerentes à construção civil como carpinteiros, pedreiros, pintores, calceteiros ou cabouqueiros. Para além deste universo, onde se engloba o maior número de profissionais, surgem os outros ofícios inerentes à vida quotidiana na cidade como alfaiates, padeiros, barbeiros, ourives, boticários, tecelóes, lavadeiras, latoeiros, entre muitos outros.

Vemos assim todo um bairro organizado com os ofícios inerentes à vida na cidade. A criação da freguesia das Mercês, em 1622, demonstra a importância que toda esta vasta zona rural já tinha e prova que o Bairro Alto estava praticamente consolidado ao nível do tecido urbano e da composição social. Como refere Baltasar Teles, na crónica da Companhia de Jesus "as oliveiras se transformaram em casas; os cerrados desabitados se mudaram em edifícios grandiosos ${ }^{23}$. O enquadramento e os elementos de destaque são as igrejas e conventos, que se constituem como pólos agregadores e enriquecedores, contribuindo para uma certa nobilitação da zona ${ }^{24}$.

${ }^{21}$ Arquivo Municipal de Lisboa (AML), Livro do lançamento e serviço que a cidade de Lixboa fez a el rei nosso senhor o ano de 1565, 1565. Publicado na colecção "Documentos para a história da cidade de Lisboa" com o título Livro do lançamento e serviço que a cidade de Lixboa fez a El Rei nosso senhor o ano de 1565, Lisboa, CML, 1947.

${ }^{22}$ AML, Livro do lançamento e serviço que a cidade de Lixboa fez a el rei nosso senhor $o$ ano de 1565, fls. 308-356v.

${ }^{23}$ Baltasar Teles, cit., vol. 2, p. 101.

${ }^{24}$ Maria Calado e Vítor Matias Ferreira, cit., p. 46. 
Em toda esta área ocidental da cidade o enquadramento e os elementos de destaque são as igrejas e conventos, que se constituem como pólos agregadores e enriquecedores, contribuindo para uma certa nobilitação da zona ${ }^{25}$. A Igreja de Nossa Senhora do Loreto foi o primeiro edifício de grandes dimensões erigido sobre a muralha e as Portas de Santa Catarina. Pertença da comunidade italiana estabelecida em Lisboa foi fundada em 1518, tornando-se sede de uma paróquia especial que agregava todos os habitantes daquela nacionalidade $^{26}$. Em consequência de decisão de D. Sebastião é concedida à Irmandade de Nossa Senhora do Loreto a posse do torreão da muralha fernandina situado a norte da igreja para a ampliação da mesma. Obra que vai alterar definitivamente a fisionomia de Lisboa ocidental permitindo a abertura e o crescimento urbanístico para fora das portas da cidade ${ }^{27}$.

A Igreja das Chagas de Cristo teve a sua origem numa primitiva ermida da invocação de Nossa Senhora da Piedade ou das Chagas inaugurada pelos marítimos da carreira da Índia em 1542 e onde era venerada uma imagem da virgem que segundo a tradição fora trazida do oriente ${ }^{28}$. A Igreja de Nossa Senhora da Encarnação, iniciada em 1698 por iniciativa de D. Elvira Maria de Vilhena, condessa de Pontével e dama da rainha D. Catarina de Bragança, foi inaugurada em 1708, substituído a primitiva Ermida do Alecrim onde se instalara a sede da paróquia, saída da Igreja do Loreto, em 1679. Na rua dos Calafates, foi edificado o colégio dos Catecúmenos,

${ }^{25}$ Maria Calado e Vítor Matias Ferreira, cit., p. 46.

${ }^{26}$ Manuel Ferreira da Silva, "Igreja de Nossa Senhora do Loreto", Dicionário de História de Lisboa, pp. 543-545.

${ }^{27}$ AML, Livro 1. ${ }^{\circ}$ de consultas e decretos de D. Sebastião, doc. 64, fls. 103-104v. - D. Sebastião ordena a demolição do torreão para ampliação da igreja, 10 Julho 1573; Livro $1^{\circ}$ de Contratos, doc. 20, fls. 89-94v. - Tomada de posse do torreão pela Confraria de Nossa Senhora do Loreto, 20 Janeiro 1577; Id., doc. 21, fls. 95-96v. - Câmara de Lisboa aprova a ampliação da igreja, 24 Abril 1577.

${ }^{28}$ José da Felicidade Alves, "Igreja das Chagas de Cristo", Dicionário da História de Lisboa, pp. 270-271. 
instituído pelo Cardeal Rei D. Henrique em 1579, para catequização dos muçulmanos ${ }^{29}$.

Para além das casas religiosas que vão proliferando pelo Bairro Alto de São Roque, "naquele lugar até então quase solitário, começou a surgir em volta de sua casa e igreja [Companhia de Jesus] uma nobilíssima povoação (...) só poucos meses tinham passado sobre a fundação do primeiro de $\mathrm{Ou}$ tubro de 1553, e já algumas famílias nobres se estabeleciam na vizinhança da casa professa" ${ }^{30}$.

Logo no século XVI, os Duques de Bragança abandonam o seu paço na encosta do Castelo, para o lado ocidental da cidade. $\mathrm{O}$ mesmo fazendo os Condes de Vimioso, que mandam erigir um palácio junto à Rua do Alecrim ${ }^{31}$. Perto da ermida de São Roque, também os Condes da Vidigueira erigem o seu palácio. "A par da mais alta nobreza, aparentada com a família real, era natural que outras grandes famílias quisessem disfrutar do novo bairro. Seguiram-se, a pouco e pouco, os Costa (Soure), os Rebelos, os Melos (Ficalho), os Carvalhos (Pombal), os Salema ${ }^{32}$, os Cunha e Menezes (Lumiares), os Mendonça (Marim-Olhão), para nomear só algumas famílias que mandaram erigir grandes casas"33.

Os livros de "cordeamento", existentes no acervo do Arquivo Municipal de Lisboa, são uma fonte fundamental para o estudo da urbanização da cidade. Estes livros constituídos

${ }^{29}$ João Bautista de Castro, Mappa de Portugal Antigo e Moderno, Lisboa, Officina Patriarcal de Francisco Luiz Ameno, 1763, tomo 3, p. 267

${ }^{30}$ Francisco Rodrigues, cit., vol. I, p. 633.

${ }^{31}$ Norberto de Araújo, Inventário de Lisboa, Lisboa, Câmara Municipal de Lisboa, 1950, fasc. 8, pp. 43-47.

${ }^{32}$ AML, Estudos e projetos urbanísticos, [Planta do piso térreo do palácio dos Salemas no Bairro Alto] (PT/AMLSB/CMLSB/UROB-PU/09/00080).

${ }^{33}$ Completo levantamento dos palácios construídos no Bairro Alto em Hélder Carita, Bairro Alto. Tipologias e Modos Arquitectónicos, Lisboa, CML, 1990, pp. 69-92. Para a história do Palácio Pombal, Norberto de Araújo, cit., fasc. 8, pp. 37-40; para a história do Palácio Marim-Olhão, id., fasc. 9, pp. 45-47; para a história do Palácio dos Conde de Soure, id., fasc. 9, pp. 25-27. 
por requerimentos, autos de vistoria e despachos, testemunham a necessidade de licenciamento tanto para a aprovação de obras novas como para reconstruções ou alteraçôes à traça inicial do edifício. Assim, todas as obras estavam sujeitas a esta licença emanada pela Câmara da cidade de Lisboa. Estes documentos fornecem-nos hoje dados de extrema importância para a história das diversas edificações no Bairro Alto. As licenças concedidas tinham por base critérios rígidos que a Câmara da cidade obrigava a cumprir. Analisando alguns dos dados verificados nos cordeamentos pedidos, concluímos que a largura da via pública, a altura das sacadas e os impedimentos da colocação de degraus assentavam em medidas rígidas, que tinham que ser cumpridas ${ }^{34}$. $\mathrm{O}$ alinhamento das frontarias também era ponto a manter ${ }^{35}$.

${ }^{34}$ AML, Livro de Cordeamentos 1710-1719, de 1 de Fevereiro de 1713 - Diogo Jorge pede licença para colocar portas e sacadas numas casas na rua da Rosa das Partilhas; Livro de Cordeamentos 1710-1719, de 6 de Outubro de 1713 - Simão Nunes Rangel pretendia colocar janelas de sacada. Refere-se no cordeamento que a Rua da Rosa ficaria com 26 palmos e meio de largo, não tomaria nada de publico e as sacadas que se assentassem ficariam com a altura de 14 palmos para cima e nos portais que se assentarem se não poriam degraus.

35 AML, Livro de Cordeamentos 1710-1719, de 20 de Junho de 1713 - André de Sousa de Oliveira, pretendia fazer obras nas suas casas desmanchando a fachada "sempre cordeando direito com as paredes das casas vizinhas e pelos seus alicerçes velhos sem tomar nada de público; Livro de Cordeamentos 1710-1719, de 4 de Julho de 1718 - Francisco de Melo pede cordeamento para continuar a obra "sem tomar nada de público e as sacadas que assentar hão-de ficar em altura de catorze palmos para cima e não há-de por degraus na rua nem meter grades baixas de aranha que saquem da parede para fora"; Livro de Cordeamentos 1730-1737, de 11 de Maio de 1734 - O Desembargador Francisco Nunes Cardeal pede cordeamento pois pretende continuar um "quarto alto" nas casas em que vive na rua da Atalaia para o que necessita de novo cunhal. 


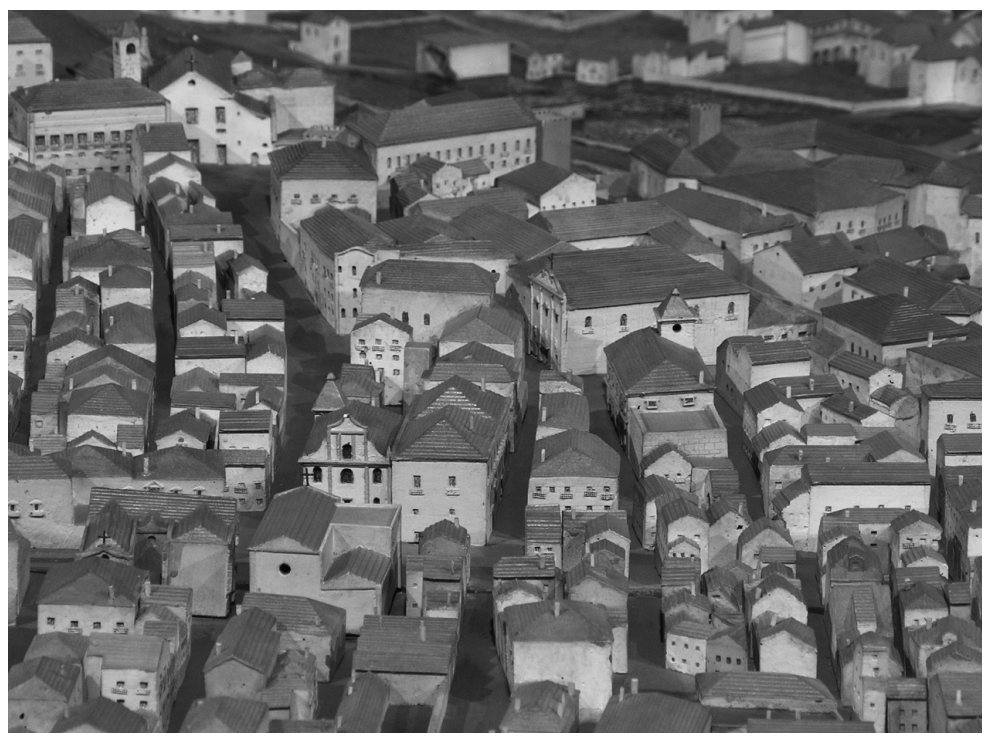

Fig. 3 Igreja de Nossa Senhora do Loreto e a Igreja de São Roque - século XVIII (Maqueta de Lisboa Antes do Terramoto - Museu da Cidade de Lisboa. (C) Fotografia José Vicente DPC/DMC/CML).

Actualmente situada em local de grande referência histórica e turística - entre a praça Luís de Camóes e o largo do Chiado, a Igreja de Nossa Senhora do Loreto enquadrou muitos dos acontecimentos que se viveram na cidade de Lisboa. O largo das Duas Igrejas, como ficou popularmente conhecido, foi alvo de grandes transformaçôes urbanísticas e palco de manifestações, festas e recepções que durante os séculos mais recentes caracterizam a vida na cidade. Desde a construção da muralha fernandina com uma das principais portas de entrada nesta área, à reedificação da igreja após Terramoto de 1755, o enquadramento urbanístico com a construção da escadaria ${ }^{36}$, passando pelas simples actividades do

${ }^{36}$ Sobre a construção da escadaria de acesso á igreja ver AML, Livro $10^{\circ}$ de Consultas e decretos de D. Afonso VI, fls. 111-112v. e Livro 2. ${ }^{\circ}$ de registo de consultas e decretos de D. Pedro II, fls. 81-83v. 
quotidiano como o abastecimento de água no chafariz do Loreto, estamos perante ocorrências que a documentação à guarda do Arquivo Municipal de Lisboa testemunha ao investigador interessado.

Longe de preocupações de estudo exaustivo, este pequeno artigo visa contribuir para o estudo da Igreja de Nossa Senhora do Loreto e da zona envolvente da cidade, explorando alguns documentos do alargadíssimo acervo do Arquivo $\mathrm{Mu}$ nicipal de Lisboa. 